\title{
REVIEW
}

\section{No frills management of epistaxis}

\author{
S C L Leong, R J Roe, A Karkanevatos
}

Emerg Med J 2005;22:470-472. doi: 10.1136/emj.2004.020602

Epistaxis is a common, potentially life threatening, emergency but first line medical staff are often not adequately trained in its management. This paper presents an illustrated step by step guide to the management of epistaxis by junior doctors in the emergency department.

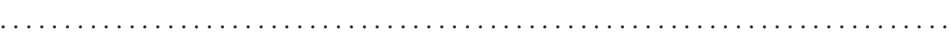

See end of article for authors' affiliations

Correspondence to:

Dr S C Leong, 34A Upper Parliament Street, Liverpool L8 1TE;'Icheel@ doctors.org.uk

Accepted for publication 9 January 2005
E pistaxis is a common presentation in accident and emergency (A\&E) departments in the UK. The estimated incidence is 108/ 100000 population per year. ${ }^{1}$ Epistaxis is usually treated in general practice or by junior doctors in A\&E. A recent survey in the UK illustrated that many A\&E departments did not have even the basic facilities to treat epistaxis. Furthermore, junior doctors in A\&E have been found to be inadequately trained to manage this potentially life threatening emergency. ${ }^{2}$

We present a practical systematic approach to the management of epistaxis intended for use by inexperienced staff working in A\&E or ENT.

All right, let's start.

\section{STEP 1: FIRST AID}

(1) Relax! A nosebleed is a distressing experience for the patient (and perhaps for you too); so it is always helpful to try to remain calm around your patient.

(2) Suit up! Epistaxis can be a very bloody affair (no pun intended). Protect yourself. Remember the "3 Gs": gloves, gown, and goggles.

(3) Resuscitate your patient first if necessary. Don't forget your ABCs.

(4) Take a quick but comprehensive history (see box 1).

(5) The patient should be sitting up and bending slightly forwards to prevent blood from tracking into the pharynx. Most bleeds are from the anterior septum.

(6) Ask the patient to apply direct pressure by pinching the lower part of the nose for 1015 minutes (fig 1).

(7) At the same time, the patient should be mouth breathing and spitting all blood or saliva into a bowl.

(8) An ice pack placed over the dorsum of the nose may help with haemostasis.

(9) Most nosebleeds will stop with direct pressure. Proceed to cauterising the bleeding points now. You may want to ask a nurse to help you at this stage.

\section{Box 1: History taking.}

Consider the following:

- Which side is bleeding?

- Estimated amount of blood loss

- Is it recurrent?

- Is it in the pharynx?

- Recent trauma?

- Symptoms of hypovolaemia?

- Past medical history and current medication-for example, aspirin and warfarin

\section{STEP 2: CAUTERY}

(1) We suggest the following equipment:

(a) lidocaine and phenylephrine spray

(b) headlight or torch

(c) nasal specula

(d) suctioning facilities

(e) silver nitrate cautery sticks.

(2) As with any procedure, explain to the patient what you intend to do.

(3) Inspect the nasal cavity and clear out any blood or clots with gentle suction.

(4) Spray the nasal cavity with the lidocaine and phenylephrine spray and wait for a few minutes. Although spraying the nasal cavity is not widely practised, we have found this to
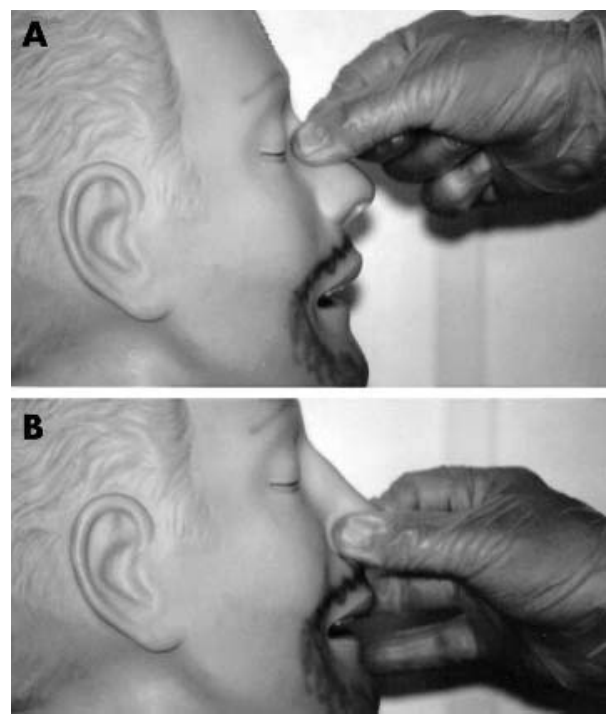

Figure 1 Applying direct pressure to the nose. (A) Incorrect. (B) Correct. 


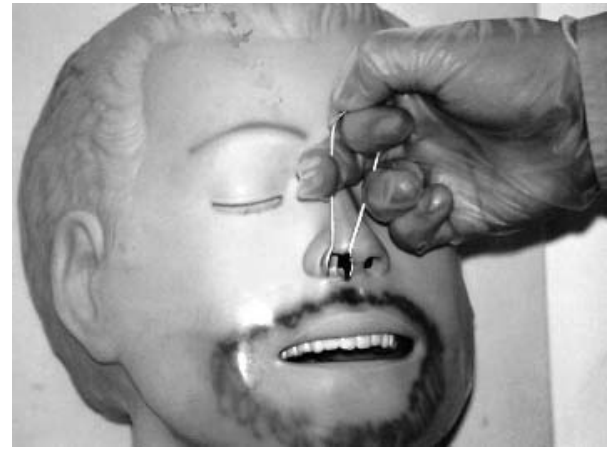

Figure 2 How to hold a nasal speculum.

be of value. Phenylephrine is a potent vasoconstrictor and lidocaine provides local anaesthesia when you inspect the nose for cautery.

(5) Adequate illumination is important. If a headlight is not available, an otoscope can be used.

(6) Inspect the nasal cavity (fig 2). An obvious site of bleeding may be noted or indicated by a prominent surface blood clot, which is usually at the anterior septum.

(7) Once you have identified the bleeding points, apply the cautery for approximately 10 seconds (box 2 ). Start from the edge of the bleeding point and move centrally in a radial fashion.

(8) If there is no more active bleeding, the patient may be discharged with an advice leaflet providing there are no other medical problems.

\section{STEP 3A: ANTERIOR PACKING}

(1) If bleeding continues, you may have to consider nasal packing.

(2) Some of the equipment you will need is (see fig 3):

(a) headlight or torch

(b) forceps

(c) ribbon gauze impregnated with bismuth iodoform paraffin paste (BIPP) or Vaseline gauze or Merocel packs (Medtronic, Inc., Minneapolis, USA)

(d) K-Y jelly (Alpharma USPD Inc., Lincoln, NC) or Naseptin cream (Alliance Pharmaceuticals Ltd, Chippenham, UK).

\section{Merocel packing}

(1) Lubricate the Merocel pack with a generous amount of $\mathrm{K}-\mathrm{Y}$ jelly or Naseptin cream.

\section{Box 2: Silver nitrate}

Precautions:

- It cauterises everything it touches. So don't touch the facial skin, nasal alae, or other nasal mucosae. Use the nasal speculum, and brace your cauterising hand. Ask your patient to remain still and explain why.

- Never cauterise both sides of the nasal septum. This can result in septal perforations.

- It may not work if bleeding is active.

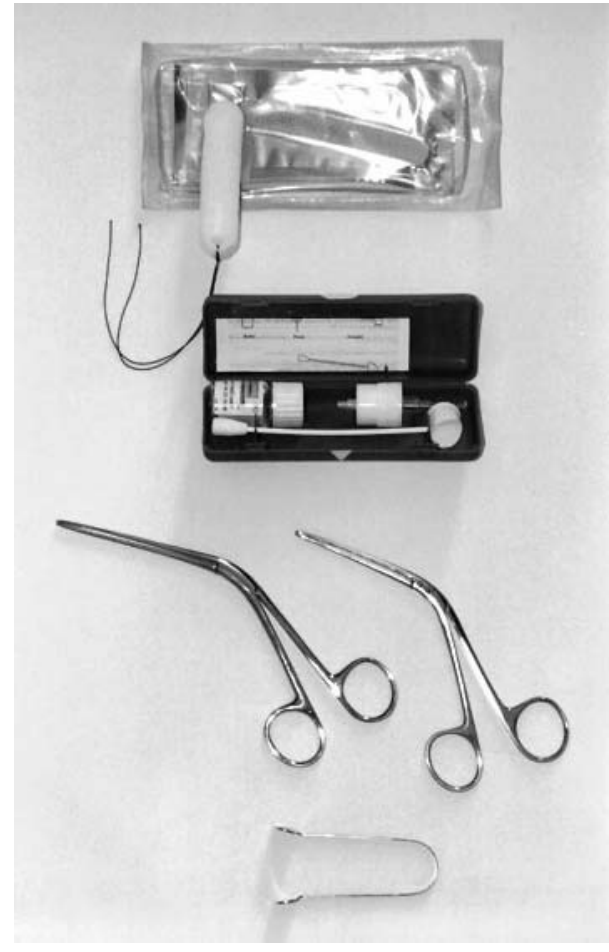

Figure 3 Equipment required for Merocel packing. Top to bottom: Merocel pack, lidocaine/phenylephrine spray, forceps, nasal speculum.

(2) Remember that the floor of the nasal cavity extends horizontally so advance your pack in the manner shown in fig 4.

(3) Ensure that you advance the Merocel pack all the way into the nose.
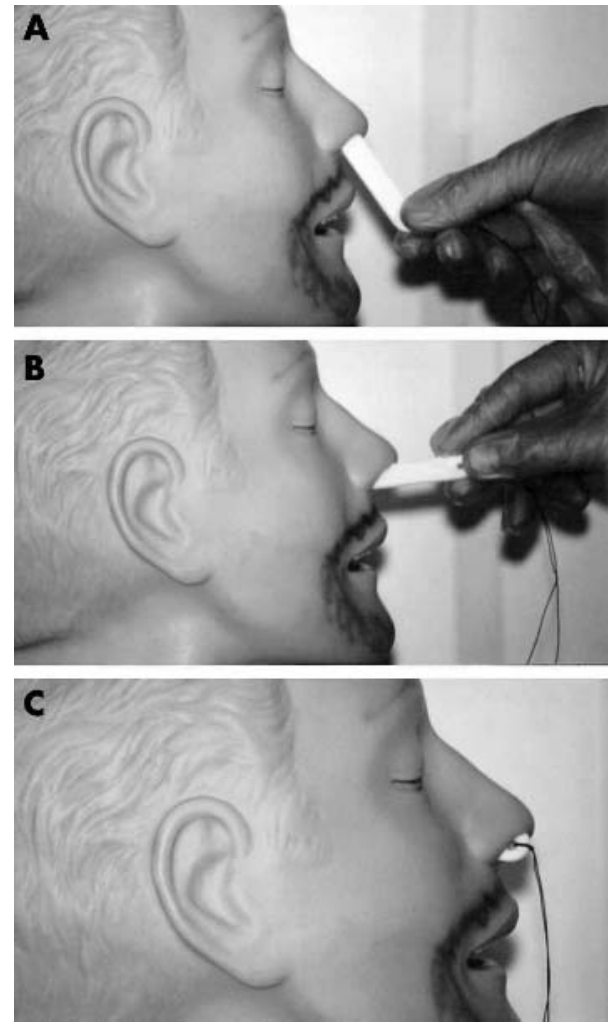

Figure 4A-C Advancing the Merocel pack horizontally. 


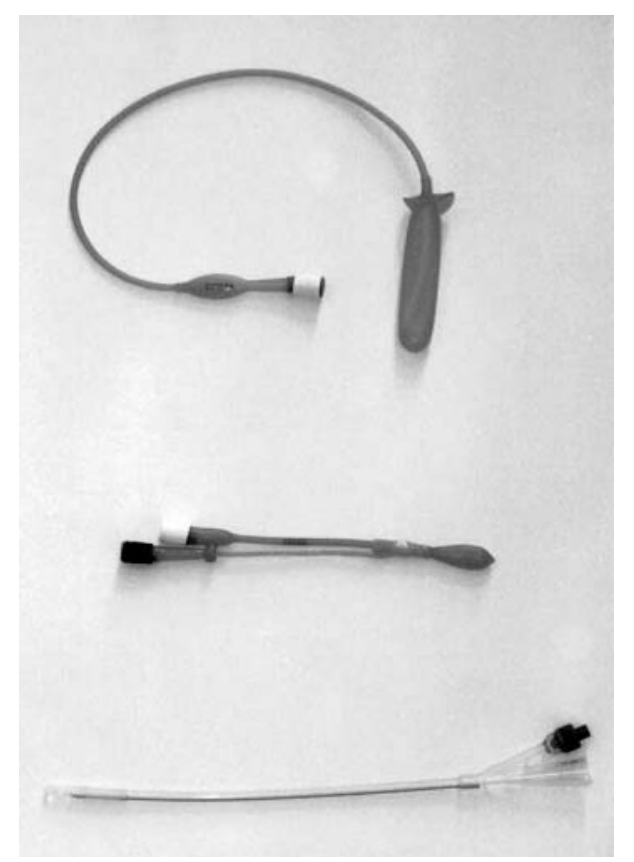

Figure 5 Various types of postnasal pack. Top to bottom: Brighton and Simpson ballons, Foley catheter.

(4) Pack the other side as well.

(5) Secure the string to the cheek with some tape. Apply a nasal bolster.

\section{Ribbon gauze packing}

(1) Pick the gauze with the forceps approximately $10-15 \mathrm{~cm}$ from the tip.

(2) Pack the nasal cavity starting from the floor upwards. Remember, the floor of the nose is the roof of the mouth (which is the hard palate).

(3) Continue to do so by layering the gauze until you reach the cavity roof. Pack the cavity tightly.

(4) Both ends of the ribbon gauze should both protrude from the nostril. You don't want one end dangling down the nasopharynx and causing the patient to gag, or worse, eliciting laryngospasm!

(5) Secure the gauze. Apply a nasal bolster to control dripping and secretions.

\section{STEP 3B: POSTNASAL PACKING}

Continued haemorrhage despite an anterior pack may be due to a posterior bleed.

(1) At this stage, consider placing a postnasal pack. You will need help from a nurse but if you feel out of your depth, take help from your colleagues.
(2) Many postnasal packs are available commercially, for example Simpson and Brighton balloons (fig 5). The most commonly used is a Foley catheter.

(3) Remove the anterior pack and re-examine the nasal cavity.

(4) Suction as required. Spray the nasal cavity again.

(5) Hold the tip of the catheter with a pair of forceps.

(6) With the patient breathing through the mouth, feed the catheter horizontally along the nasal floor.

(7) Once you see the tip passing beyond the palate into the oropharynx, inflate the balloon with $10 \mathrm{ml}$ of saline.

(8) Gently pull the catheter forwards until you feel resistance. The inflated balloon now acts as a tamponade on the posterior bleed.

(9) At this stage, consider anterior packing (see Step 3A above).

(10) Secure the catheter with a clip to prevent inadvertent removal. Also ensure that the catheter is not pressing on the nose as alar necrosis may occur. This can be prevented by applying gauze around the nostril. ${ }^{3}$

\section{GENERAL MEASURES}

- All patients with a nasal pack should be admitted. Routine bloods should be sent off. All patients need not have a coagulation profile done. ${ }^{4}$ It depends on the history!

- Remember to resuscitate the patient if necessary.

- Patients should be encouraged to rest. Some patients may benefit from a low dose of diazepam for a calming effect. They should also receive mouth washes to dislodge clots in the oropharynx.

- Most anterior packs should be removed after 24 hours and the nasal cavity re-examined in case cautery is required.

- Remember! Epistaxis is frequently idiopathic; however, it can be a manifestation of a possible underlying pathology. Your patient should undergo further investigations according to the history.

\section{Authors' affiliations}

S C L Leong, R J Roe, A Karkanevatos, Otolaryngology Department, Royal Liverpool University Hospital, Liverpool, UK

Competing interests: none declared

\section{REFERENCES}

1 O'Donnell M, Robertson G, McGary GW. A new bipolar diathermy probe for the outpatient management of adult acute epistaxis. Clin Otolaryngol 1999;24:537-41.

2 Wild CD, Spraggs PDR. Treatment of epistaxis in Accident and Emergency departments in the UK. J Laryngol Otol 2002;1 16:597-600.

3 Ismail H, Buckland JR, Harries PG. The prevention of alar necrosis in Foley catheter fixation in posterior epistaxis. Ann R Coll Surg Engl 2004;86:30.

4 Thaha MA, Nilssen ELK, Holland S, et al. Routine coagulation screening in the management of emergency admission for epistaxis - is it necessary? J Laryngol Otol 2000;114:38-40. 